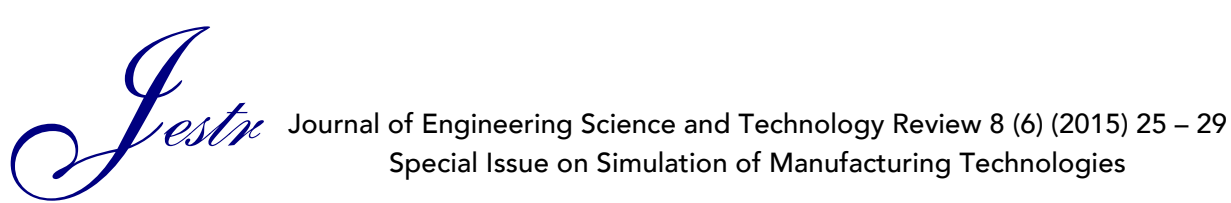

Conference Article

\title{
Local Ion Nitriding of 38KhMYuA Steel with Glow Discharge in a Hollow Cathode
}

\author{
V.V. Budilov, K.N. Ramazanov, Yu.G. Khusainov, I.V. Zolotov and S.V. Starovoitov
}

Ufa state aviation technical university, Ufa, Russia - 450008

Received 2 September 2015; Accepted 11 September 2015

\begin{abstract}
The effect of local ion nitriding in glow discharge with the hollow cathode effect (HCE) on microstructure, phase composition and microhardness of steel $38 \mathrm{KhMYuA}$ was studied. Optical microscopy of the nitrided layer was carried out. The kinetic of diffusion layer growth was investigated.
\end{abstract}

Keywords: local ion nitriding, glow discharge, hollow cathode effect, microhardness.

\section{Introduction}

It is a known fact [1] that the majority of machine parts fail working in conditions of friction and cyclic loads, originating on the surface of the material due to pitting and the development of microscopic cracks. Surface hardening improves the reliability and durability of these parts.

Literature analysis showed that ion nitriding is one of the most common methods of structural and phase modification from a variety of surface hardening methods [2]. Ion nitriding has its advantages over traditional methods (gas nitriding, nitriding in liquids, etc.) as there is: (1) a possibility of obtaining diffusion layers of specific phase composition, producing good surface finish, allowing nitriding surface-passivating materials without additional processing; providing an economical and environmentally friendly process [3].

Protecting by using an overmeasure is often used to remove fragile, brittle phases which have formed on the material surface after the ion nitriding process. This leads to the need of nitriding the workpiece surface to a greater depth, taking into account an allowable value of 100-200 $\mu \mathrm{m}$. For example, to obtain a diffusion layer of $250 \mu \mathrm{m}$ deep (excluding a reasonable allowance) on $38 \mathrm{KhMYuA}$ steel surface, ion nitriding time can take up to 24 hours [4]. Therefore, despite of all of the advantages of ion nitriding process this method requires a long process time. It has been experimentally proved in the works of Kreindel Yu.E., Lemeshev N.M., Slosman A.I., Budilov V.V., Agzamov R.D. and others that application of hollow cathode effect (HCE) for ion nitriding in glow discharge can significantly intensify the process of diffusion compared to that without HCE $[5,6,7]$.

It is known that machine parts undergo local loads during operation, as in example the contact surface of gear teeth or shaft bearings. In such cases, there is no need of hardening of every surface of the part, and it is only

\footnotetext{
* E-mail address: kamram@rambler.ru ISSN: 1791-2377 @ 2015 Kavala Institute of Technology. All rights reserved.
}

sufficient to process the working surface. In this paper we introduce the method of local ion nitriding based on creating HCE only on work areas of the part surface to avoid the grinding operation which is used for finishing.

The aim of this work is to investigate the influence of ion nitriding with $\mathrm{HCE}$ on microstructure, phase composition and microhardness of steel $38 \mathrm{KhMYuA}$.

\section{Methods of Study}

Experiments were carried out on the multifunctional setup for thermal and thermochemical treatment in vacuum ELU$5 \mathrm{M}$. Samples of thermal pretreated (quenching at $930^{\circ} \mathrm{C}$ and tempering at $600^{\circ} \mathrm{C}$ ) steel $38 \mathrm{KhMYuA}$ were sputtered in argon at a pressure of $10 \mathrm{~Pa}$ for $15 \mathrm{~min}$, and then ion nitrided in an atmosphere of nitrogen, argon and acetylene (Ar 70\%, $\mathrm{N} 225 \%, \mathrm{C} 2 \mathrm{H} 25 \%$ ) and at pressure of $60 \mathrm{~Pa}$ for 12 hours. Part of the sample was covered with a mesh for screening (Fig. 1). HCE occurred in the cavity formed between the screen and the surface of the sample. Process temperature was set not higher than $550^{\circ} \mathrm{C}$.

A Zeiss Axiotech 25HD microscope was used for optical microscopy investigations. Samples were etched in solution of $5 \% \quad \mathrm{HNO} 3$ and $95 \% \mathrm{C} 2 \mathrm{H} 5 \mathrm{OH}$. Microhardness was measured on a Struers Duramin michohardness tester. X-ray analysis was performed with the help of DRON-4 difractometer.

In case of local ion nitriding with HCE the heating rate of the surface covered by the mesh screen is greater than the heating rate of the entire surface of the part. Therefore, there is irregular temperature distribution during the nitriding process

To select the optimal process parameters and increasing the nitriding efficiency, computer modelling was carried out. The computer model that allows the prediction of the temperature distribution during local ion nitriding with HCE and the depth of diffusion zone after treatment was developed. The theoretical model of the ion nitriding process is based on the heat equation and Fick's equation. 


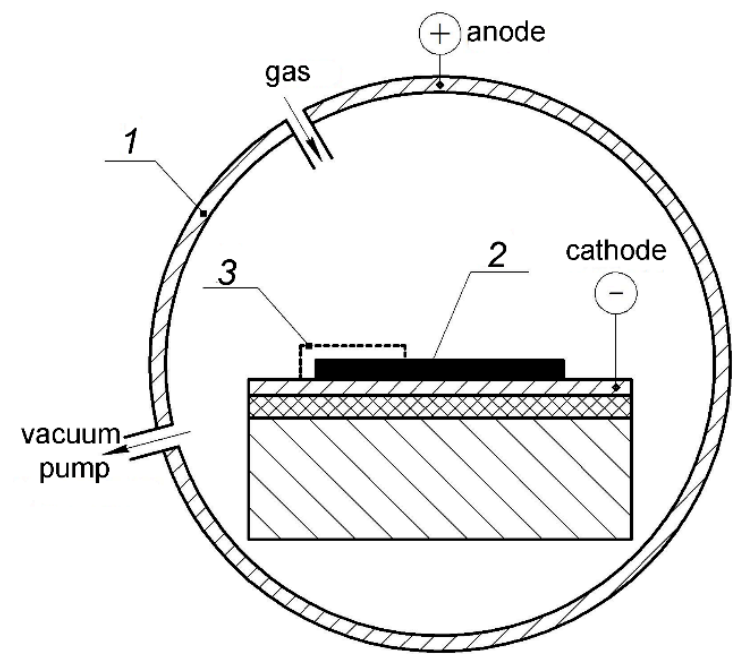

Fig.1. Experimental setup: 1 - vacuum chamber, 2 - sample, 3 - screening mesh.

At the beginning the concentration of nitrogen in steel is equal to zero, the temperature is assumed to be $298 \mathrm{~K}$ :

$c_{0}=0 ; T_{0}=293 \mathrm{~K}$

The third type of boundary condition is used in the model of local ion nitriding process [8].

$$
(-D \nabla c) n=k_{m}\left(c_{b}-c\right)
$$

where $D$ is the diffusion coefficient, c is the concentration of nitrogen, $n$ is boundary's normal vector, $k_{m}$ is the mass transport coefficient, $c_{b}$ is the bulk concentration of nitrogen.

$$
n(-h \nabla T)=q_{0}
$$

where $h$ is the heat transfer coefficient, $T$ denotes to temperature, $q_{0}$ is the thermal flux through the boundary:

$$
q_{0}=j_{i} U
$$

where $j_{i}$ is the ion current density, $U$ - discharge voltage.

And for radiation losses:

$$
-n(-h \nabla T)=\varepsilon \sigma\left(T_{a m b}^{4}-T^{4}\right)
$$

where $T_{a m b}$ is environment temperature, $\varepsilon$ is emissivity coefficient, $\sigma$ is the Stefan-Boltzmann's constant.

During ion nitriding with HCE there is increased ion concentration areas under screen, which leads to ion current density increasing and hence to local heating intensification. However, heat radiation into environment remains uniform throughout surface of workpiece (Fig. 2).

\section{Results and discussing}

From calculations, the temperature distribution after 8 hours of local ion nitriding of gear (Fig. 3, a) and the heating curve of the toothing (Fig. 3, b) were obtained. The process temperature of toothing is about $550^{\circ} \mathrm{C}$.

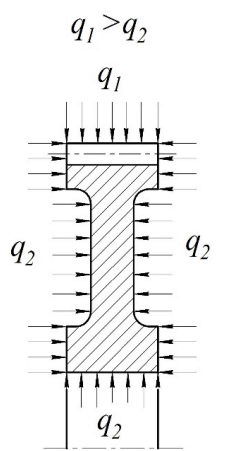

(a)

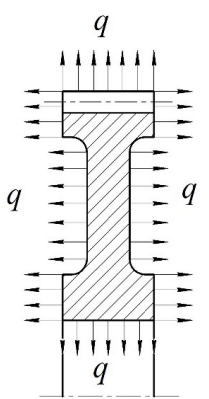

(b)

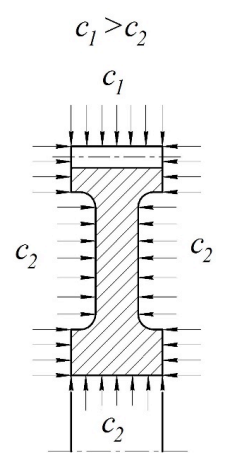

(c)
Fig. 2. Scheme of heating by ions energy (a), radiation into environment $(b)$ and distribution of nitrogen atoms throughout surface of a workpiece $(c)$.

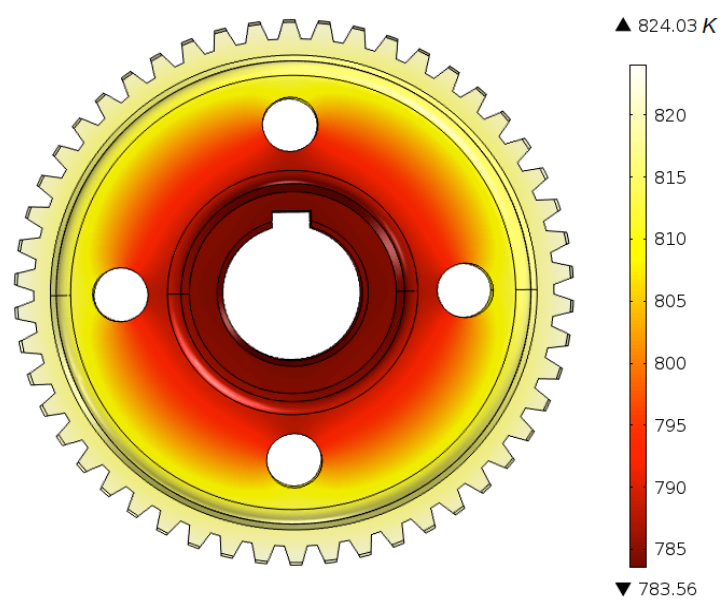

(a)

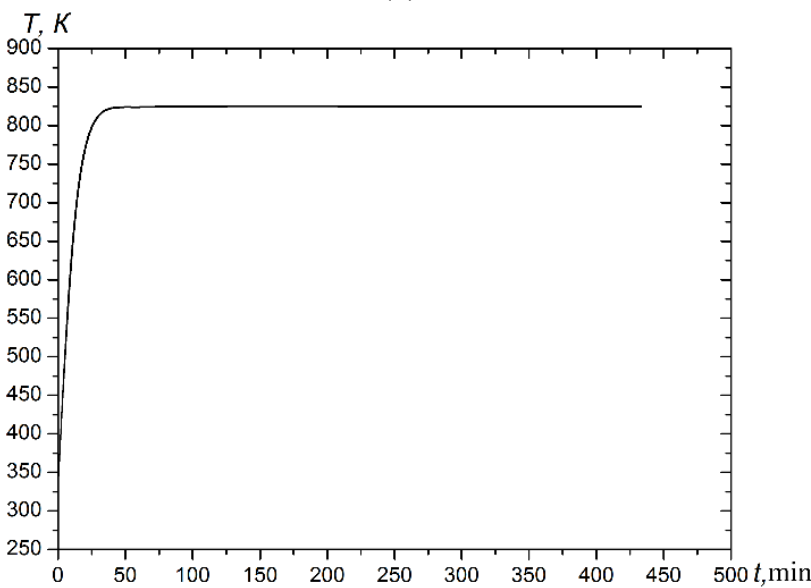

(b)

Fig. 3. Results of computer modelling: temperature distribution after 8 hours of local ion nitriding of gear (a) and heating curve of toothing (b).

Analysis of this curves shows that after reaching the maximum value of $550^{\circ} \mathrm{C}$, temperature remains constant throughout the process. It can be linked to a balance between heat flux input and thermal radiation losses. The time necessary to reach the process temperature is about $40 \mathrm{~min}$ (heating rate is $0.2^{\circ} \mathrm{C}$ per sec).

Microstructure of samples of $38 \mathrm{KhMYuA}$ before ion nitriding is shown in Fig. 4.

As a result of thermal treatment, tempering troostite is observed as a dark needle-like structure in the light fields of 
martensite [8]. The surface micro-hardness steel 38HMYUA

after quenching and tempering is $370 \pm 20 \mathrm{HV}_{100}$.

Photos of nitrided sample microstructure are presented in Fig. 5.

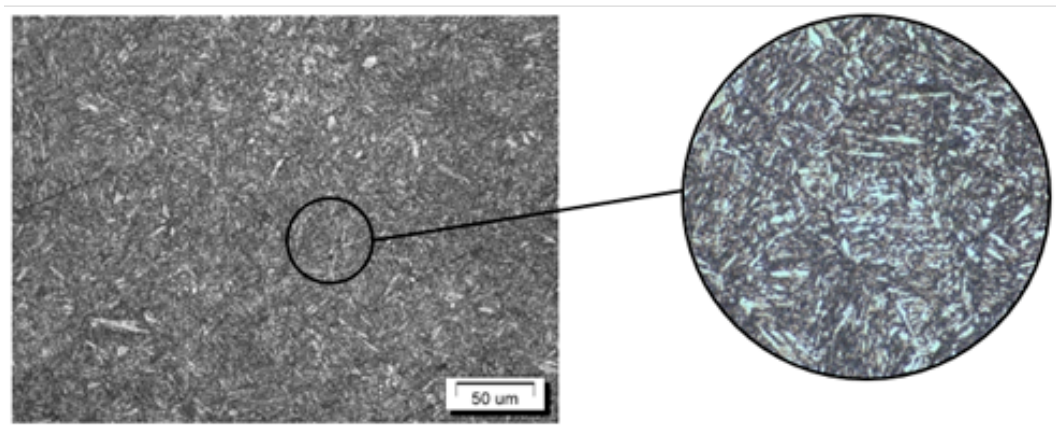

Fig. 4. Microstructure of steel $38 \mathrm{KhMYuA}$ after quenching at $940^{\circ} \mathrm{C}$ and tempering at $600^{\circ} \mathrm{C}$
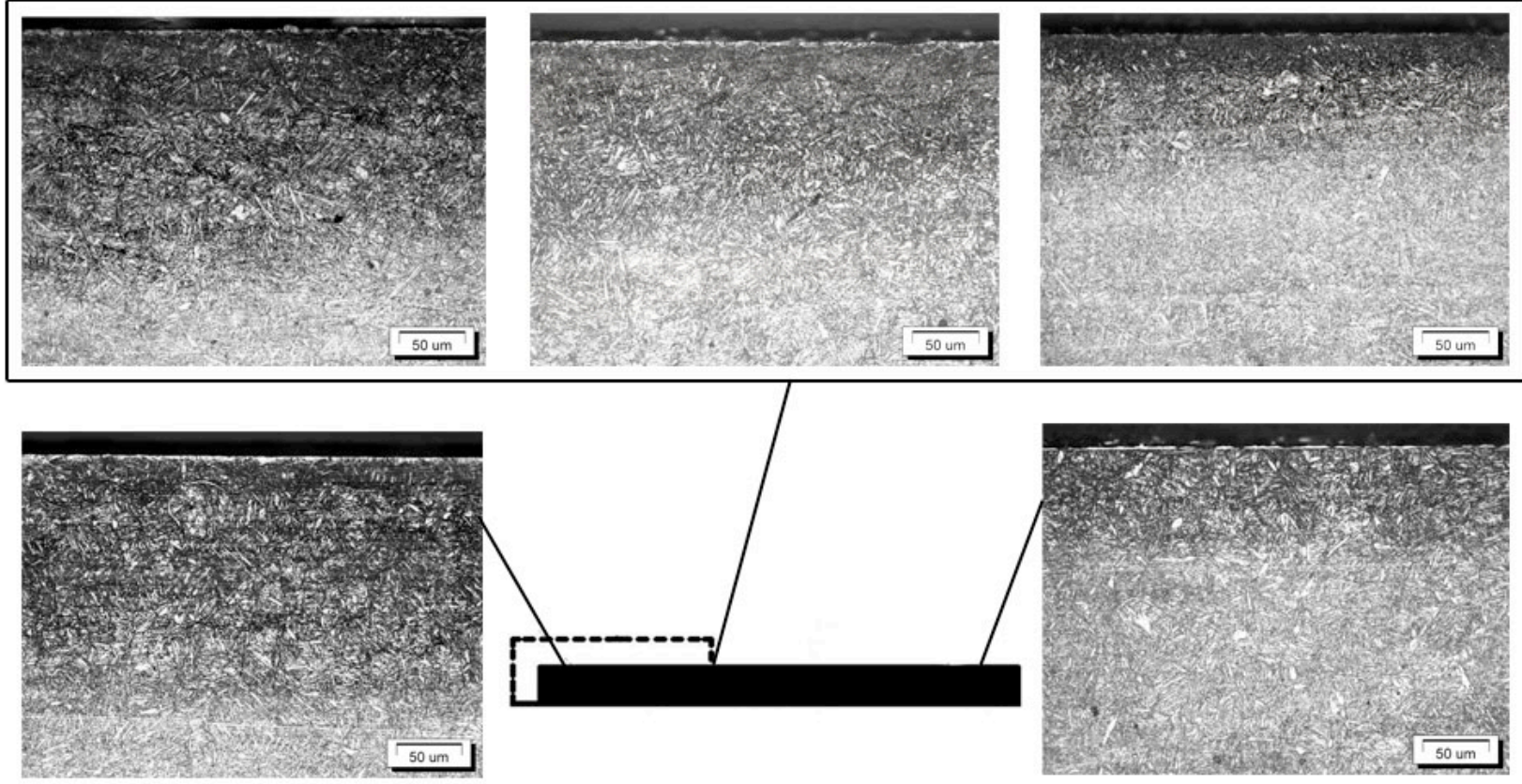

Fig. 5. Microstructure of ion nitrided sample: affected by HCE area, transition zone and unaffected by HCE area

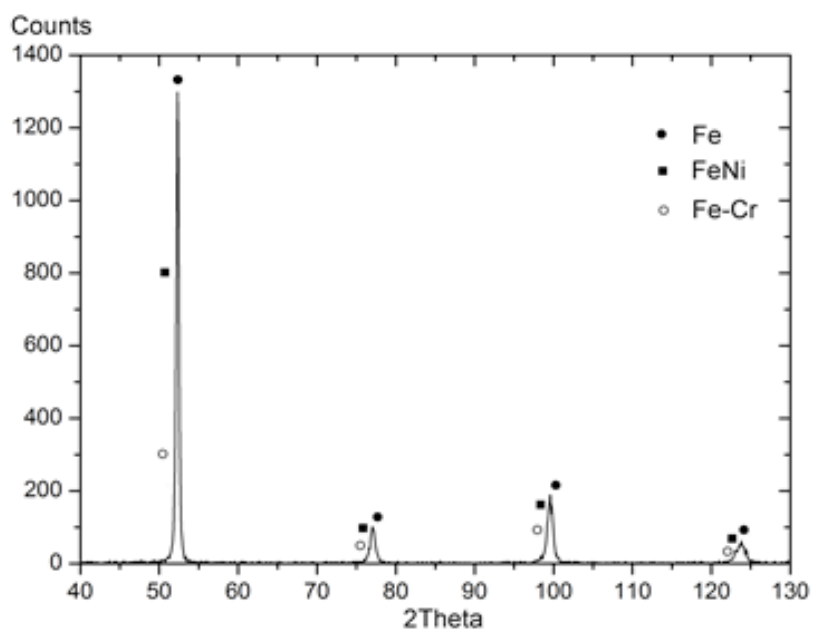

Fig.6. Diffraction pattern of $38 \mathrm{KhMYuA}$ surface after quenching and tempering

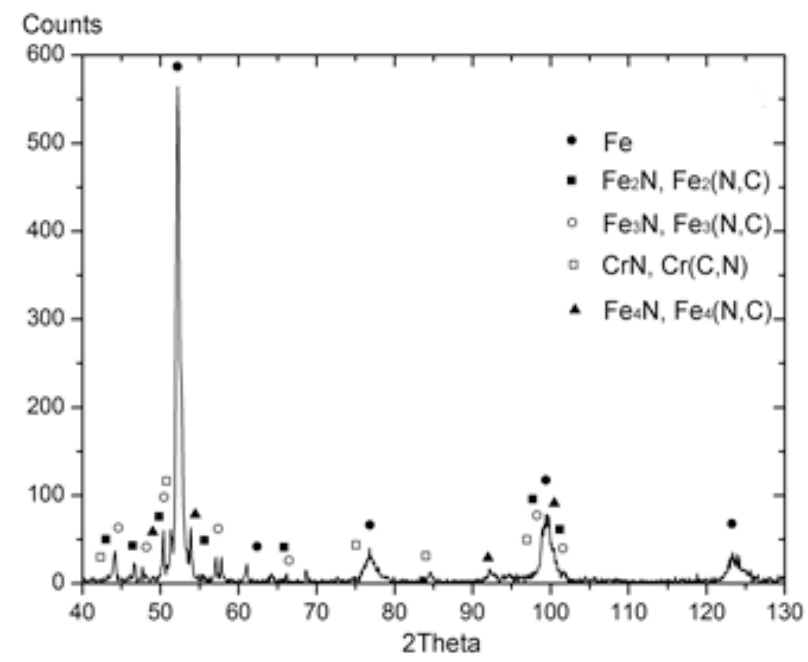

Fig. 7. Diffraction pattern of nitrided with HCE sample 
V.V. Budilov, K.N. Ramazanov, Yu.G. Khusainov, I.V.Zolotov, S.V. Starovoitov/

Journal of Engineering Science and Technology Review 8 (6) (2015) 25 - 29

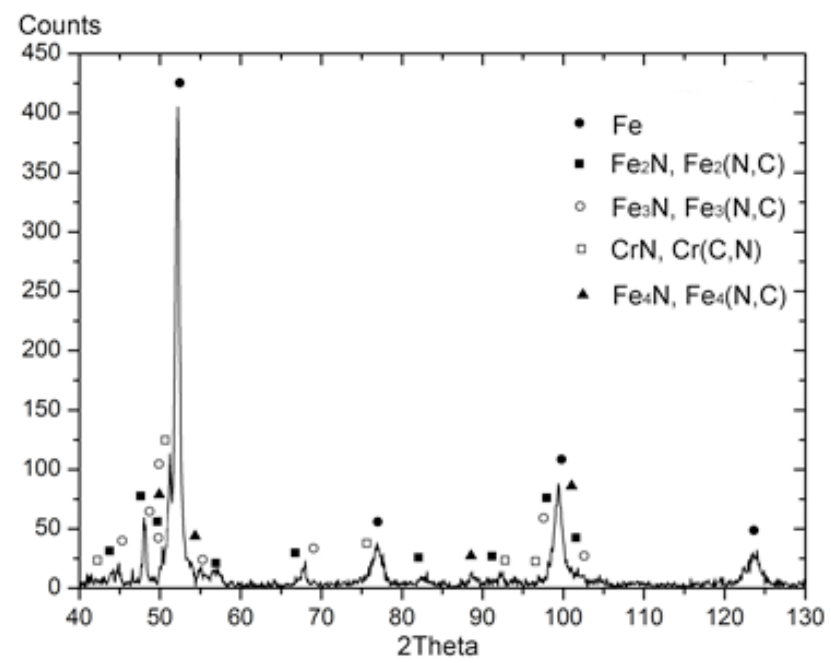

Fig. 8. Diffraction pattern of conventional ion nitrided sample surface.

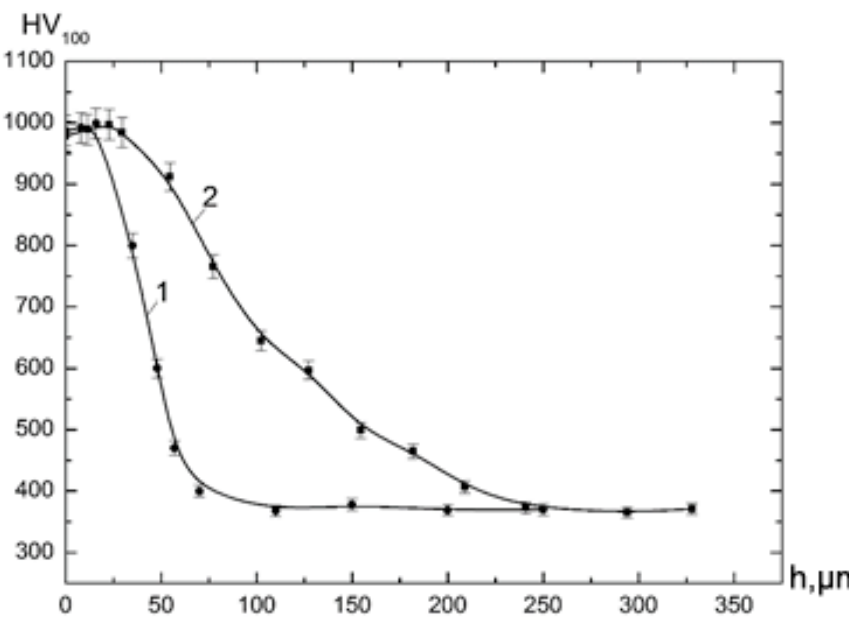

Fig. 9. Microhardness distribution throughout diffusion layer depth after 12 hours of local ion nitriding ( 1 - affected by HCE zone, 2 - unaffected bu HCE zone).
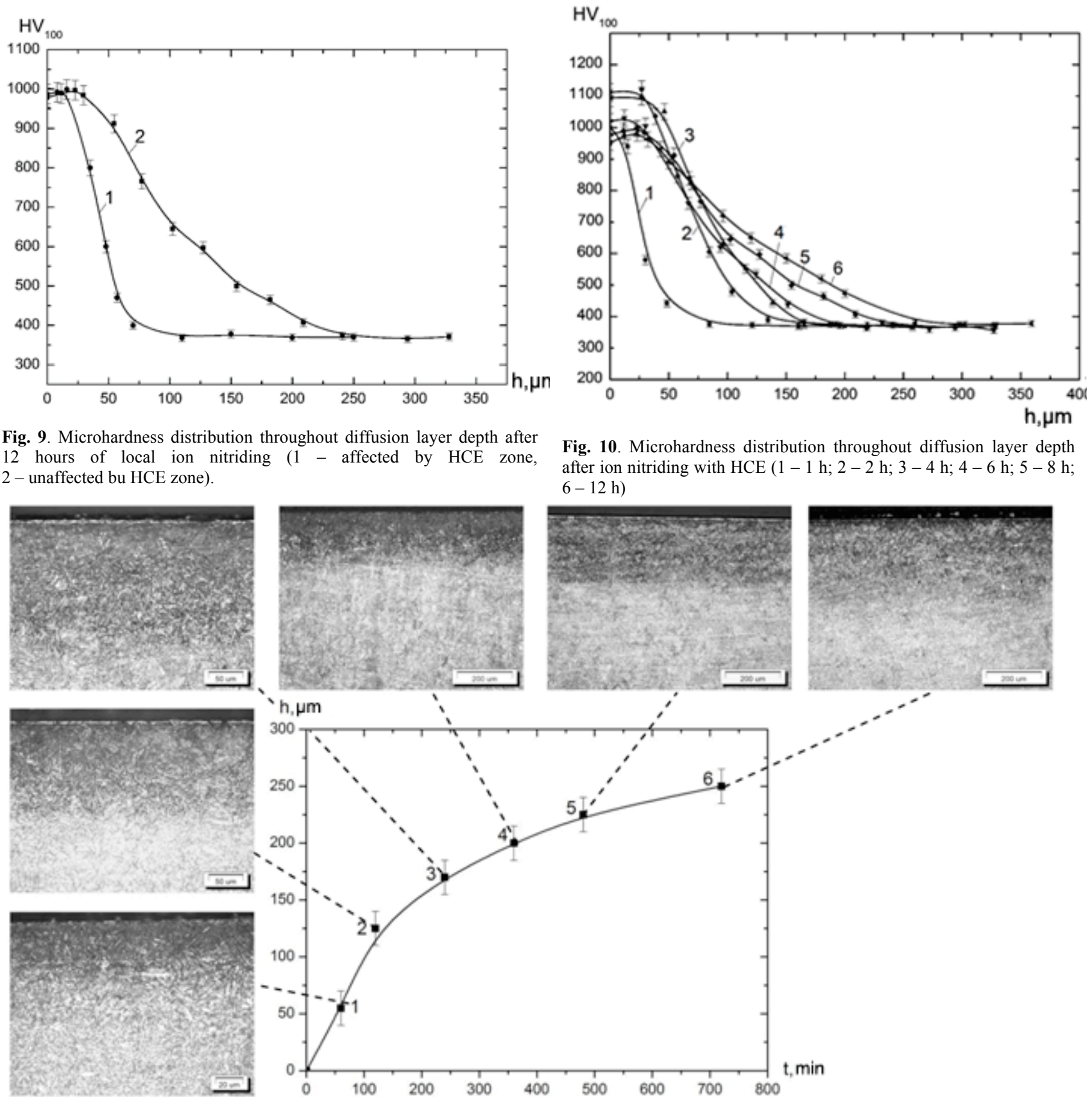

Fig. 10. Microhardness distribution throughout diffusion layer depth after ion nitriding with $\operatorname{HCE}(1-1 \mathrm{~h} ; 2-2 \mathrm{~h} ; 3-4 \mathrm{~h} ; 4-6 \mathrm{~h} ; 5-8 \mathrm{~h}$; $6-12 \mathrm{~h})$
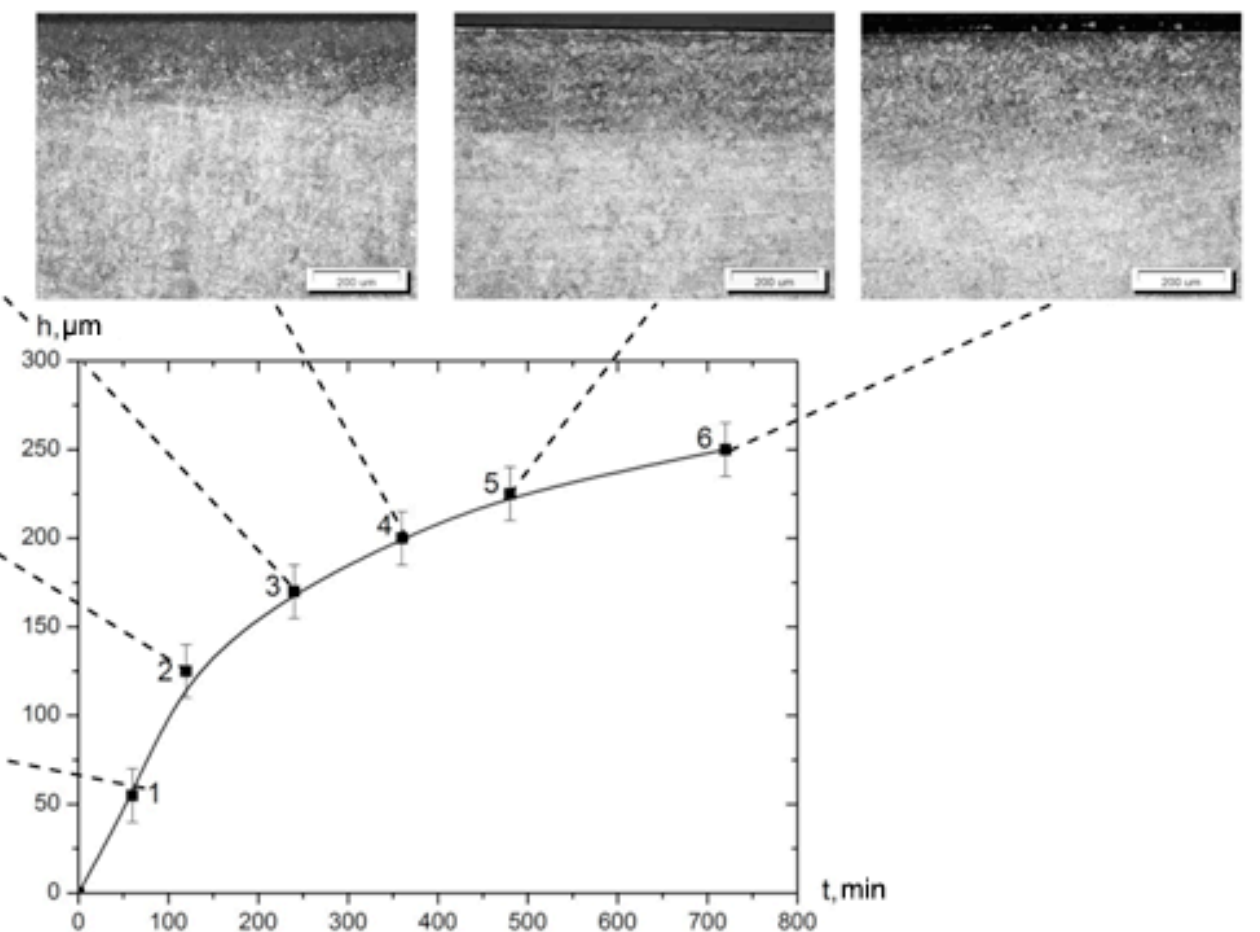

Fig. 11. Kinetics of hardened layer growth thickness during ion nitriding with HCE. 
Investigation of nitrided sample microstructure showed the existence of three zones: a zone affected by HCE (covered surface area), an unaffected zone and a transition zone. A thicker dark diffusion layer covered by the screen area can be observed due to the greater gradient of saturation element in the cathode cavity during ion nitriding [7]. Transition from diffusion layer to the core material is smooth, with the width of the transition zone is $3 \mathrm{~mm}$.

$\mathrm{X}$-ray analysis was performed to investigate phase composition of the steel surface. The diffraction patterns of the sample before ion nitriding are presented in Fig. 6.

The diffraction patterns showed presence of $\mathrm{Fe}, \mathrm{Fe}-\mathrm{Cr}$, Fe-Ni solid solutions patterns.

In Fig. 7 the diffraction pattern of nitrided with HCE sample surface presented. It shows presence of $\varepsilon$-phases $\mathrm{Fe}_{2-3}(\mathrm{~N}), \mathrm{Fe}_{2-3}(\mathrm{~N}, \mathrm{C}), \gamma$-phases $\mathrm{Fe}_{4} \mathrm{~N}, \mathrm{Fe}_{4}(\mathrm{~N}, \mathrm{C})$, and also phases of chromium nitrides and carbonitrides $\mathrm{CrN}$, $\mathrm{Cr}(\mathrm{C}, \mathrm{N})$.

The diffraction pattern of conventional ion nitrided sample showed the same phases with a lower peak intensity. Iron and carbonitrides formed can be linked to the presence of acetylene in the gas atmosphere. Thus, in a carburizing atmosphere $\gamma^{\prime}$ nitride dissolves carbon and turns into carbonitride $\mathrm{Fe}_{3}(\mathrm{~N}, \mathrm{C})$. This phase has good wear resistance and less brittle than cementite $\mathrm{Fe}_{3} \mathrm{C}$ or nitrides $\mathrm{Fe}_{2-3} \mathrm{~N}$ [5].

Microhardness measurements (Fig. 9, 10) allowed to estimate hardened case depth after local ion nitriding with HCE.

Fig. 9 shows that the covered area has up to 2.5 times thicker hardened layer compared to uncovered areas.

The process time of ion nitriding with HCE significantly affects the microhardness of the finished surface. This phenomenon occurs due to coagulation of nitride and carbide particles and softening of material. With increasing the nitriding time microhardness distribution evens out without abrupt transitions to the core material. It is associated with a decrease of concentration of the dissolved nitrogen in the $\alpha$-phase [2]. The maximum microhardness moves to a $20-60 \mu \mathrm{m}$ depth with increasing of process time due to the significant accumulation of $\varepsilon$ - and $\gamma$ ' phases in this area [2].

To study the rate of hardened layer growing during ion nitriding with $\mathrm{HCE}$, the influence of process time on the diffusion case depth was investigated (Fig. 11).

It was established that saturation during nitriding with HCE obeys the inverse parabolic law, like any diffusion process. Therefore, saturation slows down during the process.

\section{Conclusions}

Three zones form after ion nitriding with HCE: the zone affected by HCE (covered surface area), the unaffected zone and the transition zone.

When protected by a screen the area has an up to 2.5 times thicker diffusion layer compared to uncovered area after $12 \mathrm{~h}$ of ion nitriding with HCE. Transition from the diffusion layer to the core material is smooth.

$\varepsilon$-phases $\mathrm{Fe}_{2-3}(\mathrm{~N}), \mathrm{Fe}_{2-3}(\mathrm{~N}, \mathrm{C}), \gamma$-phases $\mathrm{Fe}_{4} \mathrm{~N}, \mathrm{Fe}_{4}(\mathrm{~N}, \mathrm{C})$, and also phases of chromium nitrides and carbonitrides $\mathrm{CrN}$, $\mathrm{Cr}(\mathrm{C}, \mathrm{N})$ form on the surface of $38 \mathrm{KhMYuA}$ steel after local ion nitriding with HCE. HCE leads to an increase of intensity of this phases due to the relatively high concentration of nitrogen on steel surface.

\section{References}

[1] V.M. Zinchenko, Surface engineering gears methods of chemicalthermal treatment, Moscow: Publishing House of the MSTU N.E. Bauman, Russian Federation, 2001. [in Russian]

[2] B.N. Arzamasov, A.G. Bratukhin, Yu.S. Eliseev, T.A. Panayoti, Ion thermos-chemical treatment of alloys, Moscow, MGTU im. Baumana, 1990. [in Russian]

[3] I.M. Pastukh, Theory and practice of low hydrogen nitriding by glow discharge, Kharkov, NNTs KhFTI, 2006. [in Russian]

[4] S.A. Gerasimov, L.I. Kuksenova, V.G. Lapteva, Structure and wear resistance of nitrided structural steels and alloys, Moscow: Publishing House of the MSTU N.E. Bauman, Russian Federation, 2012. [in Russian]

[5] Yu.E. Kreindel, N.M. Lemeshev, A.I. Slosman, "Hollow cathode effect of nitriding in a glow discharge", Electronic treatment of materials, vol. 6, p. 38-47, 1990. [in Russian]

[6] V.V. Budilov, R.D. Agzamov, K.N. Ramazanov, "Tecnology of ion nitriding in glow discharge with hollow cathode", MiTOM, vol. 7, pp. 25-29, 2007. [in Russian]

[7] V.V. Budilov, K.N. Ramazanov, Yu.G. Khusainov, I.V. Zolotov, "Application of effect hollow cathode in local nitriding steel parts 16H3NVFMB-SH”, Vestnik UGATU, vol. 18, no 1(62), p.32-36, 2014. [in Russian]

[8] V.V. Budilov, K.N.Ramazanov, Yu.G. Khusainov, I.V. Zolotov, "Application of the hollow cathode effect in local ion nitriding of machine parts", Proceedings of Higher Education. Physics., no. 10(3), pp. 109-112, 2014. [in Russian] 